\title{
Se Status Prediction by Food Intake as Compared to Circulating Biomarkers in a West Algerian Population
}

\author{
Moussa Belhadj ${ }^{1, *}$, Latifa Sarra Kazi Tani ${ }^{1,2}$, Nouria Dennouni Medjati ${ }^{1}$, Yahia Harek ${ }^{1}$ (D), \\ Majda Dali Sahi ${ }^{1}$, Qian Sun ${ }^{3}$, Raban Heller ${ }^{3}{ }^{(D}$, Ammaria Behar ${ }^{1}$, Laurent Charlet ${ }^{2}$ and \\ Lutz Schomburg ${ }^{3, *(\mathbb{D})}$
}

1 Analytical Chemistry and Electrochemistry Laboratory, Abou Bekr Belkaid University of Tlemcen, BP 119, 13000 Tlemcen, Algeria; sarra.kazitani@univ-tlemcen.dz (L.S.K.T.); nouria.dennouni@univ-tlemcen.dz (N.D.M.); y_harek63@yahoo.fr (Y.H.); fdali13@yahoo.fr (M.D.S.); beharammaria@gmail.com (A.B.)

2 Institute of Earth Science, University of Grenoble-Alpes and CNRS, BP 53, CEDEX 9, 38041 Grenoble, France; laurent.charlet@univ-grenoble-alpes.fr

3 Institute for Experimental Endocrinology, Charité-Universitätsmedizin Berlin, Corporate Member of Freie Universität Berlin, Humboldt-Universität zu Berlin, and Berlin Institute of Health, Augustenburger Platz 1, CVK, D-13353 Berlin, Germany; qian.sun@charite.de (Q.S.); raban.heller@charite.de (R.H.)

* Correspondence: moussa.belhadj@univ-tlemcen.dz (M.B.); lutz.schomburg@charite.de (L.S.); Tel.: +21-367-539-7772 (M.B.); +49-30-450-524-289 (L.S.); Fax: +49-30-450-922 (L.S.)

Received: 17 October 2020; Accepted: 20 November 2020; Published: 24 November 2020

\begin{abstract}
Algeria is the largest country in Africa, located close to the Mediterranean coastal area, where nutrients consumption varies widely. Local data on selenium composition of foods are not available. We postulated a close correlation between selenium status predictions from food consumption analysis with a quantitative analysis of circulating biomarkers of selenium status. Population characteristics were recorded from 158 participants and dietary selenium intake was calculated by 24-h recall. The average total plasma selenium was $92.4 \pm 18.5 \mu \mathrm{g} / \mathrm{L}$ and the mean of selenium intake was $62.7 \mu \mathrm{g} /$ day. The selenoprotein P concentration was $5.5 \pm 2.0 \mathrm{mg} / \mathrm{L}$ and glutathione peroxidase 3 activity was $247.3 \pm 41.5 \mathrm{U} / \mathrm{L}$. A direct comparison of the dietary-derived selenium status to the circulating selenium biomarkers showed no significant interrelation. Based on absolute intakes of meat, potato and eggs, a model was deduced that outperforms the intake composition-based prediction from all food components significantly (DeLong's test, $p=0.029$ ), yielding an area under the curve of $82 \%$. Selenium status prediction from food intake remains a challenge. Imprecision of survey method or information on nutrient composition makes extrapolating selenium intake from food data providing incorrect insights into the nutritional status of a given population, and laboratory analyses are needed for reliable information.
\end{abstract}

Keywords: selenium; monitoring; food intake; predictive model; selenoprotein P; glutathione peroxidase 3

\section{Introduction}

Selenium (Se) is an essential trace element for humans, mainly acquired through the daily diet [1]. The amount of Se in food items is variable, and it is hard to predict the Se content of a particular diet; its accumulation in plants depends on soil Se content and other soil parameters in a given area [2]. Dietary factors also determine the Se bioavailability; foods with high protein content (meat, fish, seafood) are characterised as better sources of Se, whereas high fat may impair bioavailability [3]. Most fruits and vegetables provide little Se because of their low content of protein and high content of water. The estimation of the Recommended Dietary Allowance (RDA) constitutes a considerable 
challenge, as the Se metabolism in human subjects is a complex, dynamic and a multifactorial process, depending on inflammation, genotype, sex, overall health status and other factors, and the different disease risks associated with Se deficiency do not provide a unique, population independent and universally accepted threshold for insufficient intake [4-6]. Even though the biosynthesis of certain selenoproteins is strictly dependent on a sufficiently high Se intake and shows low expression in Se deficiency, a Se deficit is not mirrored in a particular clinical phenotype [7].

This may be due to a hierarchical distribution of Se within the body and between the tissues and enzymes, as the essential selenoproteins appear to be preferentially supplied with the limiting trace element, even in times of Se deficiency [8,9]. Circulating and easily accessible selenoproteins have been established as protein biomarkers of Se status in subjects with marginal Se status, i.e., glutathione peroxidases and selenoprotein P (SELENOP), as they correlate almost linearly with Se intake $[4,10,11]$. However, with a sufficiently high Se supply, these protein biomarkers stabilize at serum Se concentrations of approximately 90 to $120 \mu \mathrm{g} / \mathrm{L}$, with SELENOP covering the broadest range of Se intake [11-13]. Serum or plasma Se concentrations below $70 \mu \mathrm{g} / \mathrm{L}$ are considered to indicate Se deficiency $[4,11,12]$. High intakes of selenomethionine are mirrored not only in selenoprotein biosynthesis but also in an increased Se content of all proteins synthesized, where selenomethionine may replace regular methionine and, e.g., leading to considerable amounts of Se in other circulating proteins, e.g., albumin [14].

The RDA in the United States was estimated based on plasma glutathione peroxidase (GPX3) activity maximisation, and set at around $55 \mu \mathrm{g} /$ day [15]. The nutrition societies of Germany, Austria and Switzerland (D-A-CH) have recommended intakes of $70 \mu \mathrm{g} /$ day for men and $60 \mu \mathrm{g} / \mathrm{day}$ for women, at a rate of approximately $1 \mu \mathrm{g}$ of Se/kg of body weight, an amount required for almost full SELENOP saturation [13]. Based on the occurrence of adverse effects, i.e., selenosis, the Tolerable Upper Intake Level (UL) for an adult is set at $400 \mu \mathrm{g} / \mathrm{day}[16,17]$. When this intake level is surpassed over an extended time period, e.g., due to the consumption of misformulated Se-containing supplements, symptoms of selenosis may develop including loss of finger-and toenails, of scalp and body hair, muscle or joint pain and fatigue [18]. Conversely, insufficient Se intake and low Se status have been associated with increased risk for malignant, cardiovascular or infectious diseases [19-21], and poor survival chances in cancer [22], sepsis [23], severe injury [24] or COVID-19 [25,26]. Accordingly, it is of high importance for the medical systems in developing and developed countries to obtain reliable information on the Se status on a population-wide scale. Different measures are used, including dietary assessments and the quantification of total serum or plasma Se or the activity of glutathione peroxidases and SELENOP as circulating biomarkers of Se status $[4,11,12,27]$.

The options in developing countries are limited, and an assessment via a 24-h food recall would enable a fast, cost-efficient and convenient way of identifying risk groups with severe Se deficiency. This study therefore aims to test whether a straightforward assessment of 24-h food recall yields valuable insights into Se status by comparing the results to laboratory biomarkers of Se status in a selected population of the largest country of Africa, i.e., in subjects residing in Western Algeria. Association between the food groups and their intake with plasma Se and SELENOP is determined, and the interrelation between the dietary assessment and the predicted values of Se intake with the analytically quantified circulating biomarkers of Se status is evaluated. Unfortunately, our hypothesis was not supported by the results and the data obtained verify the notion that Se status cannot reliably be estimated by a single 24-recall in combination with food nutritional composition tables. Obviously, the Se contents in the particular food items varied strongly and constituted no food item-specific characteristics that could be deduced from a general food data bank. The influence of the concentration and availability of Se in the soil of production [28] in combination with the knowledge of the geographical origin of the major food items consumed along with repeated food intake assessment appears to constitute the essential information for obtaining meaningful insights into the Se intake of a given population. 


\section{Materials and Methods}

\subsection{Human Samples}

This cross-sectional observational study was performed on the general population of Western Algeria, i.e., in the Tlemcen department. One hundred and fifty-eight subjects were recruited from the medical analysis laboratory at the University Hospital of Tlemcen, Algeria, from January 2018 to March 2019. A detailed and precise questionnaire on anthropometric and socio-cultural parameters was conducted by a face-to-face interview, enabling the collection of data on personal characteristics (age, gender, blood pressure and diagnosis of hypertension, smoking habits, level of education, profession, average income, marital status) along with anthropometric data (body weight and height, yielding body mass index (BMI)). The study was carried out following the Algerian law (25/2006, Resolution $\mathrm{N}^{\circ}$. 387), it was approved by the Scientific Committee of the University of Tlemcen, as well as by the Ethics and Deontology Committee of the University of Tlemcen. All participants signed an informed consent before participation. To be eligible, volunteers needed to have no history of any cancer, or a chronic illness affecting their nutritional status. Subjects following a special diet or taking dietary supplements were also excluded from the study.

\subsection{Dietary Intake Assessment}

The amount and nature of each food item consumed during the last day was calculated in grams per day from a 24-h recall. Colour pictures of food samples with the weight indicated were provided to help participants make their choices as accurately as possible [29]. The quantities were converted into Se intakes using Ciqual (2017), a food nutritional composition table available online and free of charge [30]. Finally, all the answers were reviewed and completed if necessary.

To estimate the contribution of different dietary sources to daily Se intake, the foods were divided into categories: fish and seafood, legumes (included lentils, beans, peas and chickpeas), eggs, meat, milk and dairy products, bread, fresh fruits, cereals (included pasta, rice, bread, couscous and all dishes made from flour or semolina), vegetables (included raw and cooked vegetables) and potatoes. Although potatoes and bread are included in vegetables and cereal, respectively, they were considered as separate food groups because of their high consumption rate.

\subsection{Selenium Status Assessment}

Circulating biomarkers of Se status were assessed in plasma, essentially as described [10,31]. Blood samples were collected by venipuncture into $4 \mathrm{~mL}$ heparinised tubes, plasma and erythrocytes were separated by centrifugation at $1100 \times g$ (relative centrifugal force) using a Sigma 2-16P centrifuge for $15 \mathrm{~min}$, and then they were frozen at $-80{ }^{\circ} \mathrm{C}$ until the analyses were performed. Total Se concentration in plasma was determined by total reflection X-ray fluorescence (TXRF) analysis using a spiked gallium solution as standard and a benchtop TXRF analyser (S2 Picofox, Bruker nano GmbH, Berlin, Germany), and tested for accuracy by using a Seronorm serum standard (Sero AS, Billingstad, Norway) as described [32]. Plasma SELENOP was quantified by a validated commercial SELENOP-specific ELISA (selenOtest ${ }^{\mathrm{TM}}$, selenOmed $\mathrm{GmbH}$, Berlin, Germany) as previously described [33]. Enzymatic activity of plasma GPX3 was determined by a coupled enzymatic test, monitoring the consumption of NADPH at $340 \mathrm{~nm}$ [34].

\subsection{Statistical Analysis}

Normal distribution of values was assessed by the Shapiro-Wilk test. Non-parametric test methods were assessed to investigate location shifts between groups (Mann-Whitney U test, Kruskal-Wallis test). Categorical variables were evaluated using Fisher's exact test. Relationship between parameters was tested by Spearman's correlation analysis. As this was an exploratory post-hoc analysis, all $p$-values were to be interpreted descriptively, and no adjustment for multiple testing was adopted. Variable selection was performed via stepwise AIC selection [35,36]. Differences between ROC curves were assessed by the DeLong's test for two correlated ROC curves [37]. All statistical tests used an $\alpha$-level 
of 0.05 . The results were considered as statistically significant when the $p$-value was less than 0.05 , and differences are marked as follows: $p<0.05\left(^{*}\right), p<0.01\left(^{* *}\right)$ and $\left.p<0.001{ }^{* * *}\right)$. All statistical calculations were performed with $\mathrm{R}$ version 4.0.2 [38], applying the packages "tidyr" [39], "dplyr" [40], and "pROC" [41]. Figures were created by using the package "ggplot2" [42].

\section{Results}

\subsection{Characterisation of the Study Cohort}

The characteristics of the subjects enrolled in this cross-sectional study were assessed by face-to-face interviews. One hundred fifty-eight subjects were recruited in total. The mean age was 49 (CI: 46-51) years, and the majority were female (83.7\%). On average, participants were overweight, with a mean BMI of 26.8 (CI: $26.9-28.5) \mathrm{kg} / \mathrm{m}^{2}$, and a fraction of subjects were hypertensive, current smokers and in a stable marriage. The majority of samples indicated that the subjects were non-deficient in Se status, with a small fraction only $(7.6 \%)$ exhibiting a plasma Se concentration below the consented threshold of deficiency, i.e., below $70 \mu \mathrm{g} / \mathrm{L}$ (median (IQR): $59.9(21.8,69.4)$ versus $93.7(70.8,143.2) \mu \mathrm{g} / \mathrm{L}, p<0.001$ ) (Table 1).

Table 1. Comparison of subjects classified as Se-deficient ([Se] $<70 \mu \mathrm{g} / \mathrm{L}$ ) or Se-replete.

\begin{tabular}{|c|c|c|c|c|}
\hline & Se-Deficient & Se-Replete & Total & $p$ Value \\
\hline Total number (n) & 12 & 146 & 158 & \\
\hline Age & & & & 0.728 \\
\hline median (IQR) & $45(30,69)$ & $46(19,90)$ & $46(19,90)$ & \\
\hline mean $(95 \% \mathrm{CI})$ & $47(38,56)$ & $49(46,51)$ & $49(46,51)$ & \\
\hline BMI & & & & 0.208 \\
\hline median (IQR) & $25.4(19.5,32.5)$ & $27.2(16.0,43.2)$ & $26.8(16.0,43.2)$ & \\
\hline mean $(95 \% \mathrm{CI})$ & $25.8(23.0,28.5)$ & $27.8(27.0,28.7)$ & $27.7(26.9,28.5)$ & \\
\hline Educational level & & & & 0.151 \\
\hline$<$ high school & $6(54.5 \%)$ & $68(50.0 \%)$ & $74(50.3 \%)$ & \\
\hline >high school & $1(9.1 \%)$ & $43(31.6 \%)$ & $44(29.9 \%)$ & \\
\hline high school & $4(36.4 \%)$ & $25(18.4 \%)$ & $29(19.7 \%)$ & \\
\hline Family income (k DZD) * & & & & 0.130 \\
\hline median (IQR) & $28.0(6.0,200.0)$ & $50.0(8.0,200.0)$ & $47.5(6.0,200.0)$ & \\
\hline mean $(95 \% \mathrm{CI})$ & $48.9(13.7,111.4)$ & $54.7(46.1,63.4)$ & $54.3(45.6,63.0)$ & \\
\hline Gender & & & & 0.416 \\
\hline Female & $9(75.0 \%)$ & $119(84.4 \%)$ & $128(83.7 \%)$ & \\
\hline Male & $3(25.0 \%)$ & $22(15.6 \%)$ & $25(16.3 \%)$ & \\
\hline Hypertension & & & & 0.469 \\
\hline No & $7(63.6 \%)$ & $103(75.7 \%)$ & $110(74.8 \%)$ & \\
\hline Yes & $4(36.4 \%)$ & $33(24.3 \%)$ & $37(25.2 \%)$ & \\
\hline Marital status & & & & 0.626 \\
\hline Married & $9(81.8 \%)$ & $120(88.2 \%)$ & $129(87.8 \%)$ & \\
\hline Single & $2(18.2 \%)$ & $16(11.8 \%)$ & $18(12.2 \%)$ & \\
\hline Smoking & & & & 0.510 \\
\hline No & $9(81.8 \%)$ & $95(69.9 \%)$ & $104(70.7 \%)$ & \\
\hline Yes & $2(18.2 \%)$ & $41(30.1 \%)$ & $43(29.3 \%)$ & \\
\hline SELENOP (mg/L) & & & & 0.010 \\
\hline median (IQR) & $3.84(2.21,7.17)$ & $5.20(1.19,14.21)$ & $5.11(1.19,14.21)$ & \\
\hline mean $(95 \% \mathrm{CI})$ & $4.23(3.37,5.10)$ & $5.56(5.22,5.89)$ & $5.46(5.14,5.78)$ & \\
\hline
\end{tabular}

\footnotetext{
${ }^{*}$ A median income of around 50,000 Algerian Dinars (DZD)/month is equivalent to around 330€ or 390 US-\$.
}

The groups were very similar, and neither the anthropometric nor the sociodemographic parameters tested indicated a significant difference between the groups of subjects classified as 
Se-deficient or Se-replete (Table 1). As the subjects were divided into two groups according to plasma Se concentrations, plasma SELENOP levels showed the expected difference between the groups.

\subsection{Assessment of Se Intake via the Food Categories Using Reference Composition Data}

The $24 \mathrm{~h}$ food recall data were used to quantify absolute food intakes per food category. Data were then converted into Se intakes by using the food composition information from the ANSES French Food Composition Table Ciqual 2017, and compared between the two groups of Se-deficient (plasma Se $<70 \mu \mathrm{g} / \mathrm{L}$ ) and the Se-replete (plasma Se $>70 \mu \mathrm{g} / \mathrm{L}$ ) subjects (Table 2).

Table 2. Food intake-based analysis of absolute Se intake in Se-deficient and Se-replete subjects.

\begin{tabular}{|c|c|c|c|c|}
\hline & Se-Deficient & Se-Replete & Total & $p$-Value \\
\hline $\begin{array}{l}\text { Bread (g/day) } \\
\text { mean }(95 \% \mathrm{CI})\end{array}$ & $114(45,184)$ & $154(136,171)$ & $151(134,168)$ & 0.307 \\
\hline $\begin{array}{l}\text { Cereals (g/day) } \\
\text { mean }(95 \% \mathrm{CI})\end{array}$ & $152(96,208)$ & $204(184,224)$ & $201(181,220)$ & 0.176 \\
\hline $\begin{array}{l}\text { Eggs (g/day) } \\
\text { mean }(95 \% \mathrm{CI})\end{array}$ & $0.3(-0.4,1.1)$ & $23.0(13.4,32.6)$ & $21.5(12.5,30.5)$ & 0.344 \\
\hline $\begin{array}{l}\text { Fish \& Seafood (g/day) } \\
\text { mean }(95 \% \mathrm{CI})\end{array}$ & $0.0(0.0,0.0)$ & $9.1(2.8,15.4)$ & $8.4(2.6,14.3)$ & 0.382 \\
\hline $\begin{array}{l}\text { Fresh fruits (g/day) } \\
\text { mean }(95 \% \mathrm{CI})\end{array}$ & $122.2(24.0,220.4)$ & $80.4(58.0,102.8)$ & $83.2(61.5,104.8)$ & 0.263 \\
\hline $\begin{array}{l}\text { Legumes (g/day) } \\
\text { mean }(95 \% \mathrm{CI})\end{array}$ & $53.4(48.6,155.3)$ & $41.9(24.1,59.7)$ & $42.6(25.2,60.1)$ & 0.800 \\
\hline $\begin{array}{l}\text { Meat (g/day) } \\
\text { mean }(95 \% \mathrm{CI})\end{array}$ & $67.8(17.1,118.4)$ & $39.1(28.3,49.9)$ & $41.0(30.5,51.6)$ & 0.073 \\
\hline $\begin{array}{c}\text { Milk (g/day) } \\
\text { mean }(95 \% \mathrm{CI})\end{array}$ & $56(1.9,109)$ & $85(57,113)$ & $83(57,110)$ & 0.814 \\
\hline $\begin{array}{c}\text { Potatoes (g/day) } \\
\text { mean }(95 \% \mathrm{CI})\end{array}$ & $22.2(-5.7,50.1)$ & $85.9(67.5,104.4)$ & $81.7(64.2,99.1)$ & 0.054 \\
\hline $\begin{array}{l}\text { Vegetables (g/day) } \\
\text { mean }(95 \% \mathrm{CI})\end{array}$ & $201.1(84.3,318.0)$ & $253.4(222.8,284.0)$ & $249.9(220.6,279.3)$ & 0.443 \\
\hline $\begin{array}{l}\text { Calculated Se Int } \\
\text { median (IQR) } \\
\text { mean }(95 \% \mathrm{CI})\end{array}$ & $\begin{array}{l}\text { ke }(\mu \mathrm{g} / \mathrm{day}) \\
77.0(36.6,84.8) \\
62.5(48.6,76.4)\end{array}$ & $\begin{array}{c}54.5(17.8,247.3) \\
62.7(57.0,68.3)\end{array}$ & $\begin{array}{c}55.2(17.8,247.3) \\
62.7(57.4,68.0)\end{array}$ & 0.669 \\
\hline
\end{tabular}

The diet-specific comparison of the groups with replete or marginal Se status revealed no particular food item that turned out to be significantly associated with the different Se status. Even the calculated total Se intake in the groups was not different, when comparing the subjects with measured Se deficiency (plasma Se $<70 \mu \mathrm{g} / \mathrm{L}$ ) as compared to those with higher plasma Se status.

\subsection{Comparison of Intake-Deduced Se Status with Plasma Se Status Biomarkers}

The dietary food intakes were converted to daily Se intakes by the ANSES French Food Composition Table as highlighted above (Table 2). To test whether the results align with the expectation, i.e., providing an estimate on the resulting Se status, a direct comparison of the Se intake data with the measured Se status biomarkers was conducted. To this end, the subjects were divided according to their predicted Se intake, choosing the median Se intake as the threshold, i.e., whether daily intake was below or above $55 \mu \mathrm{g} /$ day. The results indicate that the prediction of Se status based on the calculated daily Se intake and consumption pattern does not align with the Se status biomarkers measured, i.e., neither with total plasma Se nor with the protein SELENOP (Figure 1). 
A

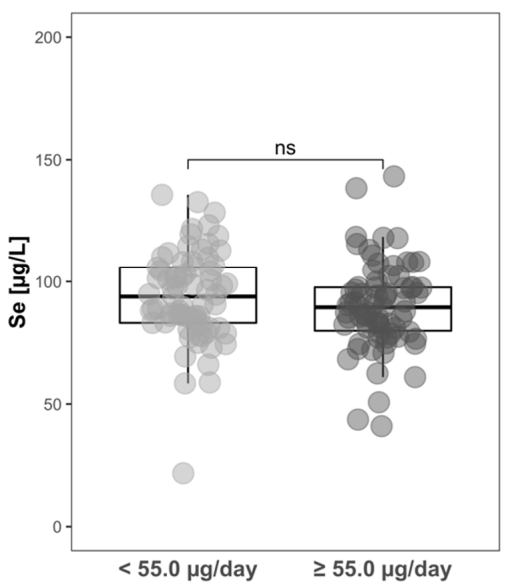

B

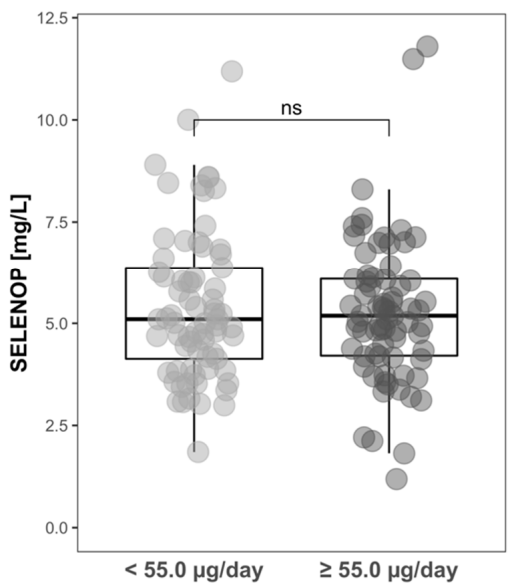

Figure 1. Comparison of calculated Se intakes per day as determined by the food recall method in combination with the food composition data in relation to the laboratory analysis of total Se and SELENOP concentrations measured in the plasma samples. No significant differences ("ns") were detected between the two groups of different Se intakes (less or more than $55.0 \mu \mathrm{g}$ Se/day) with respect to (A) total plasma Se, of (B) plasma SELENOP concentrations. Significance calculated by the Mann-Whitney $\mathrm{U}$ test, $\mathrm{ns} ; p>0.05$.

\subsection{Interrelation of Plasma Se and SELENOP Concentrations in Se-Deficient vs. Se-Replete Subjects}

The threshold for Se deficiency is generally considered to be a total serum or plasma Se concentration of $70 \mu \mathrm{g} / \mathrm{L}$. Using this boundary, the total study cohort was divided into Se-deficient or Se-replete subjects. To analyse the interrelation of the two major Se status biomarkers, i.e., total plasma Se and SELENOP, this boundary was chosen to test the correlation of both biomarkers in the Se-deficient and Se-replete groups, respectively (Figure 2). The analysis indicates that there is a relatively tight and positive correlation between plasma Se and SELENOP concentrations, particularly in the Se-deficient subjects, with a weaker interaction in Se-replete subjects with plasma Se concentrations $>70 \mu \mathrm{g} / \mathrm{L}$.

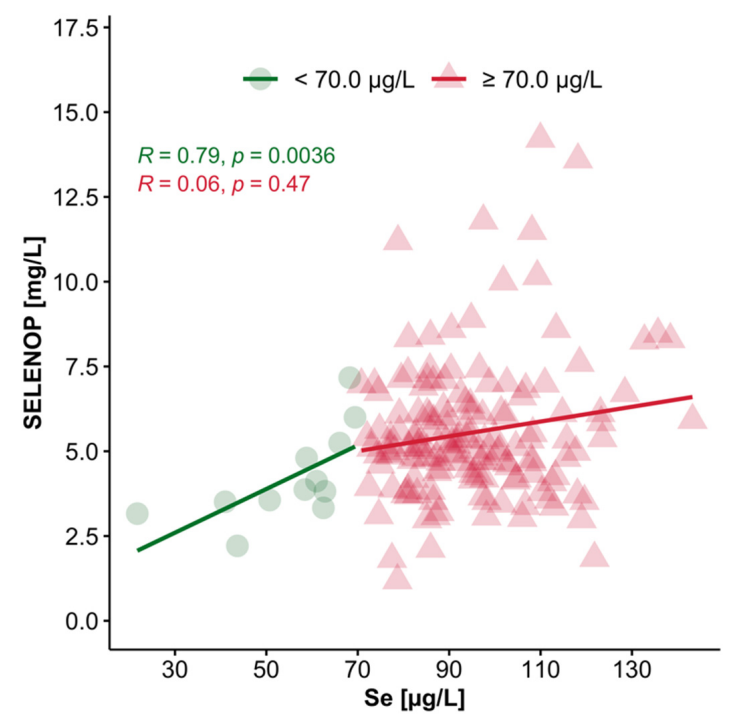

Figure 2. Correlation analysis of plasma Se with SELENOP concentrations. All of the available plasma samples $(n=134)$ of the patients enrolled were analysed for total plasma Se and SELENOP concentrations. The samples were separated into two groups based on total plasma Se deficiency into Se-deficient $(<70 \mu \mathrm{g} / \mathrm{L}$, green) and Se-replete $(>70 \mu \mathrm{g} / \mathrm{L}$, red). The biomarkers showed a significant and positive linear correlation (Spearman, $R=0.79, p=0.0036$ ) in the Se-deficient samples, whereas Se-replete subjects revealed a non-significant, positive correlation (Spearman, $R=0.06, p=0.47$ ). 


\subsection{Interrelation of GPX3 Activity with Se Intake, Plasma Se and SELENOP}

In a subset of the samples ( $n=98)$, we were able to analyse the GPX3 activity; the other samples had to be excluded for reasons of either insufficient residual volume or compromised sample quality. The results were correlated with the concentrations of Se $(R=0.16, p=0.12)$ and SELENOP $(R=0.04$, $p=0.69)$. There was no significant correlation between the estimated Se intake and the GPX3 activity in the set of samples analysed $(R=0.01, p=0.95)$.

\subsection{Deducing a Model of Food Intake according to Food Categories Predicting Se Status}

Finally, the data were used to model Se status from the data on food intake (amount and food categories) in relation to the measured biomarkers of Se status. The analyses indicate that information on the food categories eggs, meat and potatoes provided the most reliable match and outperformed any other combination of variables when compared via stepwise AIC selection (Figure 3).

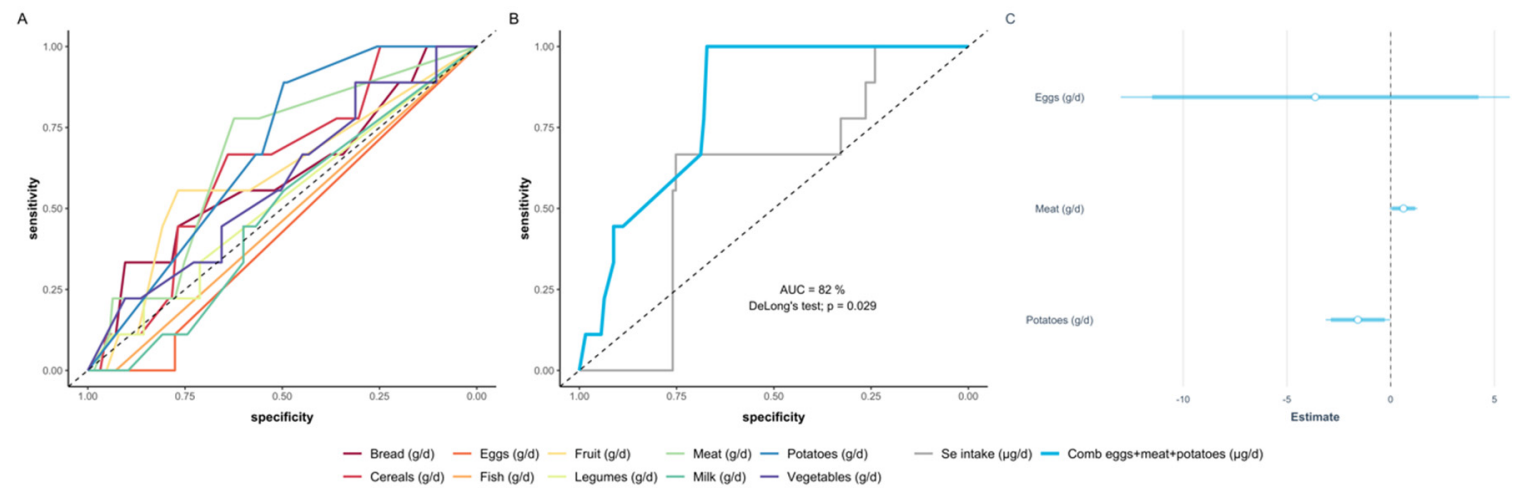

Figure 3. ROC-analysis of different food categories to differentiate between Se-deficient and Se-replete subjects. (A) Absolute intakes of several food categories (g/day) yielded similar results and poor predictive information. (B) The multiple regression model based on eggs, meat and potatoes intakes outperformed any other combination of variables via stepwise AIC selection. The final model (blue) based on these three parameters yielded a high AUC of $82 \%$, and performed significantly better compared to the model based on the calculated Se intake (grey) from all categories deduced via the available composition data (DeLong's test, $p=0.029$ ). (C) The estimates of the final model are given alongside with the corresponding confidence intervals.

\section{Discussion}

The essentiality of Se for human health is well established, and population-wide intake and status information is of high importance for the health care systems. However, the respective data are hard to obtain, and the best way to perform such analyses and how to predict Se status reliably has been intensively discussed $[4,43,44]$. In this study, we decided to compare nutritional Se intake prediction to laboratory analysis of Se status biomarkers in a North African population from Western Algeria. Our results indicate that the population on average consumes a wide variety of food items with some potentially Se-rich ingredients like sea food, meat, eggs and milk and leguminous plants. This impression is supported by the laboratory analyses of biomarkers of Se status including the most established parameters, i.e., total plasma Se, SELENOP and GPX3 $[7,12,45]$. Using the consented threshold for Se deficiency, i.e., serum or plasma Se concentrations below $70 \mu \mathrm{g} / \mathrm{L}$, only a small fraction of less than $10 \%$ of subjects needed to be classified as insufficiently supplied with the essential trace element. However, there was no meaningful concordance when comparing the deduced Se status from the food intake patterns in combination with the food composition database with the measured biomarkers of Se status from the plasma samples. The most likely explanation for the observed mismatch between deduced values and measured concentrations lies in our assumption that using food composition data on Se contents of the different food categories would faithfully mirror the quality and Se content of the food items that have been consumed by the study participants. This assumption 
and strategy may yield accurate results for fat, carbohydrate or protein intakes, but unfortunately not for the trace element Se that presents itself again as difficult to grasp and predict, likely due to its complex geochemistry and uneven distribution [46-48].

Our laboratory analyses yielded average plasma Se and SELENOP concentrations in a range similar to what we determined in different European populations [31]. We did not observe a significant difference between men and women, which was in agreement with other independent studies on micronutrient status in Algeria [49,50], and also in agreement with other large population-wide studies in Europe [31], the US [51] or in Se-deficient or Se-replete areas of China [52]. Moreover, we did not observe a higher Se status in married as compared to single subjects, in contrast to a recent study [53].

The challenge of predicting Se intake from food frequency data is not new, and other attempts have similarly struggled with poor congruence, e.g., a respective study conducted in Finland [54]. The major reason for the inconclusiveness lies most likely in the varying Se content of a given food item, as it depends mostly on the area where it was produced and the respective soil quality and Se content $[55,56]$. In Algeria, most imported food groups are cereals (including wheat, meslin and corn) which cover more than $70 \%$ of its cereals needs. The cereals are grown in different regions of the world, mainly in America and Europe [57]. Similarly, milk, dairy products and legumes from different areas of the world contribute strongly to the Algerian nutrition [58]. The variation in the import origin of these products can be expected to have an impact on our analyses, as it causes strongly varying Se concentrations in the dietary items that formed the basis for our intake assessments and predictions [59].

On top of the variable international origin of the food items consumed in Algeria, local differences in Se content of the same nutrients are also known. Taking wheat as an example, a concentration range from as low as $21 \mu \mathrm{g} / \mathrm{kg}$ in Tiaret (western Algeria) to as high as $153 \mu \mathrm{g} / \mathrm{kg}$ in Khroub (eastern Algeria) has been reported in an Algerian study [60]. According to the Algerian Interprofessional office for Cereals, France is the main foreign supplier of cereals to Algeria [61]. French soil, as well as soils in other European countries, are rather poor sources of Se (with average Se contents as follows: France; $0.03 \mathrm{mg} / \mathrm{kg}$, Finland; $0.08 \mathrm{mg} / \mathrm{kg}$, Belgium; $0.11 \mathrm{mg} / \mathrm{kg}$, Scotland; $0.17 \mathrm{mg} / \mathrm{kg}$, Sweden; $0.30 \mathrm{mg} / \mathrm{kg}$, and Norway; $0.63 \mathrm{mg} / \mathrm{kg}$ [62]) and are considered to be Se deficient [63]. Soils in other areas of the world, e.g., in the United States of America, can be richer sources of Se, with concentrations of up to $0.95 \mathrm{mg} / \mathrm{kg}$ [64].

Our data therefore highlight the need for laboratory-based analyses of Se status in a representative sample of a given population, and the challenge when trying to deduce Se status from nutritional intake data. Moreover, the data agree with prior studies reporting a relatively moderate Se status in Western Algeria, with a small fraction of subjects only displaying an insufficient daily intake. On the one hand, the globalization of the food industry and the associated transport of food items across the world pose environmental problems and contribute to climate change, but on the other hand these transports distribute the micronutrients more evenly across the populations and also into regions at risk of low supply. This noteworthy development clearly hinders food frequency-based predictions and complicates nutritional intake analyses, but it also contributes to better health by preventing severe deficiencies in areas where certain micronutrients are sparse. The complex origin of dietary Se in the average Algerian food serves as a most instructive example for this notion.

\section{Conclusions}

It appears impossible at present to correctly predict the average Se intake or resulting Se status of a given population from food intake information alone, at least as long as specific information on Se content of individual food items is not provided by the producers. Consequently, laboratory analyses of a representative sample of the population are needed to obtain the required information. To this end, different Se status biomarkers have been established and are available, and the results obtained usually agree reliably, especially in subjects with low Se status where insufficient intake causes low plasma Se levels and suppressed selenoprotein expression. Still, it would be helpful both for the health authorities and for the consumers alike to find specific information on the micronutrient contents on the commercial food items. This information should be provided at least for those nutrients that are 
imported in large amounts from remote areas of the world, in order to better justify transport, costs and virtual water economy [65], to better predict Se intakes and to more easily identify those subjects or groups at risk of insufficient Se intake. The relevance of this challenge is generally increasing, in view of the globally declining Se availability due to earth warming and climate change [66].

Author Contributions: N.D.M. conceived the study design; M.B., L.S.K.T. contributed the samples; M.B., A.B., M.D.S. conducted and analysed the face-to-face interviews for nutrient intake assessment; plasma samples were collected and processed by M.B., L.S.K.T.; SELENOP and Se measurements were performed by Q.S.; M.B., Y.H. and R.H. conducted the statistical analyses, and all the authors contributed to data interpretation; M.B., N.D.M., L.C. and L.S. prepared the first draft, and all authors contributed to the final manuscript. All authors have read and agreed to the published version of the manuscript.

Funding: We acknowledge a Profas B+ algero-french ministerial scholarship granted to L.S.K.T. and Algerian General Directorate of Scientific Research and Technological Development (DGRSDT), which allowed for development of an active collaboration between the French University Grenoble Alpes and the Algerian University Abou Bekr Belkaid, Tlemcen, Algeria. L.S. was supported by grants from the Deutsche Forschungsgemeinschaft (DFG Research Unit 2558 TraceAge, Scho 849/6-2).

Acknowledgments: We thank Vartitér Seher for excellent technical assistance. We acknowledge financial support by the Open Access Publication Fund of Charité-Universitätsmedizin Berlin.

Conflicts of Interest: L.S. holds shares in selenOmed GmbH, a company involved in Se status assessment and supplementation. The other authors declare no competing interest with respect to this study.

\section{References}

1. Stoffaneller, R.; Morse, N.L. A review of dietary selenium intake and selenium status in Europe and the Middle East. Nutrients 2015, 7, 1494-1537. [CrossRef] [PubMed]

2. Dos Reis, A.R.; El-Ramady, H.; Santos, E.F.; Gratao, P.L.; Schomburg, L. Overview of Selenium Deficiency and Toxicity Worldwide: Affected Areas, Selenium-Related Health Issues, and Case Studies. Plant Ecophysiol. 2017, 11, 209-230. [CrossRef]

3. Kieliszek, M.; Blazejak, S. Current Knowledge on the Importance of Selenium in Food for Living Organisms: A Review. Molecules 2016, 21, 609. [CrossRef]

4. Combs, G.F., Jr. Biomarkers of selenium status. Nutrients 2015, 7, 2209-2236. [CrossRef] [PubMed]

5. Burk, R.F.; Hill, K.E. Regulation of Selenium Metabolism and Transport. Annu. Rev. Nutr. 2015, 35, 109-134. [CrossRef] [PubMed]

6. Sunde, R.A.; Li, J.L.; Taylor, R.M. Insights for Setting of Nutrient Requirements, Gleaned by Comparison of Selenium Status Biomarkers in Turkeys and Chickens versus Rats, Mice, and Lambs. Adv. Nutr. 2016, 7, 1129-1138. [CrossRef] [PubMed]

7. Schomburg, L. The other view: The trace element selenium as a micronutrient in thyroid disease, diabetes, and beyond. Hormones 2020, 19, 15-24. [CrossRef] [PubMed]

8. Labunskyy, V.M.; Hatfield, D.L.; Gladyshev, V.N. Selenoproteins: Molecular pathways and physiological roles. Physiol. Rev. 2014, 94, 739-777. [CrossRef]

9. Schomburg, L.; Schweizer, U. Hierarchical regulation of selenoprotein expression and sex-specific effects of selenium. Biochim. Biophys. Acta 2009, 1790, 1453-1462. [CrossRef]

10. Hoeflich, J.; Hollenbach, B.; Behrends, T.; Hoeg, A.; Stosnach, H.; Schomburg, L. The choice of biomarkers determines the selenium status in young German vegans and vegetarians. Br. J. Nutr. 2010, 104, 1601-1604. [CrossRef]

11. Xia, Y.M.; Hill, K.E.; Li, P.; Xu, J.Y.; Zhou, D.; Motley, A.K.; Wang, L.; Byrne, D.W.; Burk, R.F. Optimization of selenoprotein $\mathrm{P}$ and other plasma selenium biomarkers for the assessment of the selenium nutritional requirement: A placebo-controlled, double-blind study of selenomethionine supplementation in selenium-deficient Chinese subjects. Am. J. Clin. Nutr. 2010, 92, 525-531. [CrossRef]

12. Hurst, R.; Armah, C.N.; Dainty, J.R.; Hart, D.J.; Teucher, B.; Goldson, A.J.; Broadley, M.R.; Motley, A.K.; Fairweather-Tait, S.J. Establishing optimal selenium status: Results of a randomized, double-blind, placebocontrolled trial. Am. J. Clin. Nutr. 2010, 91, 923-931. [CrossRef] [PubMed]

13. Kipp, A.P.; Strohm, D.; Brigelius-Flohe, R.; Schomburg, L.; Bechthold, A.; Leschik-Bonnet, E.; Heseker, H.; German Nutrition, S. Revised reference values for selenium intake. J. Trace Elem. Med. Biol. 2015, 32, 195-199. [CrossRef] [PubMed] 
14. Ward-Deitrich, C.L.; Whyte, E.; Hopley, C.; Rayman, M.P.; Ogra, Y.; Goenaga-Infante, H. Systematic study of the selenium fractionation in human plasma from a cancer prevention trial using HPLC hyphenated to ICP-MS and ESI-MS/MS. Anal. Bioanal. Chem. 2020, 657, 1-14. [CrossRef] [PubMed]

15. Panel on Dietary Antioxidants and Related Compounds. Dietary Reference Intakes for Vitamin C, Vitamin E, Selenium, and Carotenoids. In Dietary Reference Intakes for Vitamin C, Vitamin E, Selenium, and Carotenoids; National Academies Press (US): Washington, DC, USA, 2000; ISBN 0-309-06949-1.

16. Longnecker, M.P.; Taylor, P.R.; Levander, O.A.; Howe, M.; Veillon, C.; McAdam, P.A.; Patterson, K.Y.; Holden, J.M.; Stampfer, M.J.; Morris, J.S.; et al. Selenium in diet, blood, and toenails in relation to human health in a seleniferous area. Am. J. Clin. Nutr. 1991, 53, 1288-1294. [CrossRef]

17. Yang, G.Q.; Wang, S.Z.; Zhou, R.H.; Sun, S.Z. Endemic selenium intoxication of humans in China. Am. J. Clin. Nutr. 1983, 37, 872-881. [CrossRef] [PubMed]

18. Morris, J.S.; Crane, S.B. Selenium toxicity from a misformulated dietary supplement, adverse health effects, and the temporal response in the nail biologic monitor. Nutrients 2013, 5, 1024-1057. [CrossRef]

19. Hatfield, D.L.; Tsuji, P.A.; Carlson, B.A.; Gladyshev, V.N. Selenium and selenocysteine: Roles in cancer, health, and development. Trends Biochem. Sci. 2014, 39, 112-120. [CrossRef]

20. Schomburg, L.; Orho-Melander, M.; Struck, J.; Bergmann, A.; Melander, O. Selenoprotein-P Deficiency Predicts Cardiovascular Disease and Death. Nutrients 2019, 11, 1852. [CrossRef]

21. Beck, M.A.; Levander, O.A.; Handy, J. Selenium deficiency and viral infection. J. Nutr. 2003, 133, 1463S-1467S. [CrossRef]

22. Meyer, H.A.; Endermann, T.; Stephan, C.; Stoedter, M.; Behrends, T.; Wolff, I.; Jung, K.; Schomburg, L. Selenoprotein P status correlates to cancer-specific mortality in renal cancer patients. PLoS ONE 2012, 7, e46644. [CrossRef] [PubMed]

23. Forceville, X.; Vitoux, D.; Gauzit, R.; Combes, A.; Lahilaire, P.; Chappuis, P. Selenium, systemic immune response syndrome, sepsis, and outcome in critically ill patients. Crit. Care Med. 1998, 26, 1536-1544. [CrossRef] [PubMed]

24. Braunstein, M.; Kusmenkov, T.; Zuck, C.; Angstwurm, M.; Becker, N.P.; Bocker, W.; Schomburg, L.; Bogner-Flatz, V. Selenium and Selenoprotein P Deficiency Correlates With Complications and Adverse Outcome After Major Trauma. Shock 2020, 53, 63-70. [CrossRef] [PubMed]

25. Zhang, J.; Taylor, E.W.; Bennett, K.; Saad, R.; Rayman, M.P. Association between regional selenium status and reported outcome of COVID-19 cases in China. Am. J. Clin. Nutr. 2020, 111, 1297-1299. [CrossRef]

26. Moghaddam, A.; Heller, R.A.; Sun, Q.; Seelig, J.; Cherkezov, A.; Seibert, L.; Hackler, J.; Seemann, P.; Diegmann, J.; Pilz, M.; et al. Selenium Deficiency Is Associated with Mortality Risk from COVID-19. Nutrients 2020, 12, 2098. [CrossRef]

27. Serra-Majem, L.; Pfrimer, K.; Doreste-Alonso, J.; Ribas-Barba, L.; Sanchez-Villegas, A.; Ortiz-Andrellucchi, A.; Henriquez-Sanchez, P. Dietary assessment methods for intakes of iron, calcium, selenium, zinc and iodine. Br. J. Nutr. 2009, 102, S38-S55. [CrossRef]

28. Rayman, M.P. Food-chain selenium and human health: Emphasis on intake. Br. J. Nutr. 2008, 100, $254-268$. [CrossRef]

29. Voici Quelques Photos Pour Aider vos Patients à Estimer les Quantités. Available online: https://nutrition. pasteur-lille.fr/fileadmin/user_upload/nutrition/nutrigold_outil_de_calcul_pour_les_medecins.pdf (accessed on 29 October 2020).

30. ANSES French Food Composition Table Ciqual 2017. Available online: https://ciqual.anses.fr/\# (accessed on 29 October 2020).

31. Hughes, D.J.; Fedirko, V.; Jenab, M.; Schomburg, L.; Meplan, C.; Freisling, H.; Bueno-de-Mesquita, H.B.; Hybsier, S.; Becker, N.P.; Czuban, M.; et al. Selenium status is associated with colorectal cancer risk in the European prospective investigation of cancer and nutrition cohort. Int. J. Cancer 2015, 136, 1149-1161. [CrossRef]

32. Combs, G.F.; Watts, J.C.; Jackson, M.I.; Johnson, L.K.; Zeng, H.; Scheett, A.J.; Uthus, E.O.; Schomburg, L.; Hoeg, A.; Hoefig, C.S.; et al. Determinants of selenium status in healthy adults. Nutr. J. 2011, 10, 75. [CrossRef]

33. Hybsier, S.; Schulz, T.; Wu, Z.; Demuth, I.; Minich, W.B.; Renko, K.; Rijntjes, E.; Kohrle, J.; Strasburger, C.J.; Steinhagen-Thiessen, E.; et al. Sex-specific and inter-individual differences in biomarkers of selenium status identified by a calibrated ELISA for selenoprotein P. Redox Biol. 2017, 11, 403-414. [CrossRef] 
34. Flohe, L.; Gunzler, W.A. Assays of glutathione peroxidase. Methods Enzymol. 1984, 105, 114-121. [CrossRef] [PubMed]

35. Zhang, Z. Variable selection with stepwise and best subset approaches. Ann. Transl. Med. 2016, 4, 136. [CrossRef] [PubMed]

36. Akaike, H. Likelihood of a model and information criteria. J. Econ. 1981, 16, 3-14. [CrossRef]

37. DeLong, E.R.; DeLong, D.M.; Clarke-Pearson, D.L. Comparing the areas under two or more correlated receiver operating characteristic curves: A nonparametric approach. Biometrics 1988, 44, 837-845. [CrossRef] [PubMed]

38. R Development Core Team. R: A Language and Environment for Statistical Computing; R Foundation for Statistical Computing: Vienna, Austria, 2015.

39. Wickham, H. Tidyverse: Easily Install and Load the 'Tidyverse'. Available online: https:/CRAN.R-project. org/package=tidyverse (accessed on 29 October 2020).

40. Wickham, H.; Francois, R.; Henry, L.; Müller, K. Dplyr: A Grammar of Data Manipulation; R Package Version 0.4. Available online: https://CRAN.R-project.org/package=dplyr (accessed on 29 October 2020).

41. Robin, X.; Turck, N.; Hainard, A.; Tiberti, N.; Lisacek, F.; Sanchez, J.C.; Muller, M. pROC: An open-source package for R and S+ to analyze and compare ROC curves. BMC Bioinform. 2011, 12, 77. [CrossRef] [PubMed]

42. Wickham, H. Ggplot2: Elegant Graphics for Data Analysis; Springer: New York, NY, USA, 2009.

43. Thomson, C.D. Assessment of requirements for selenium and adequacy of selenium status: A review. Eur. J. Clin. Nutr. 2004, 58, 391-402. [CrossRef]

44. Al-Mubarak, A.A.; Grote Beverborg, N.; Anker, S.D.; Samani, N.J.; Dickstein, K.; Filippatos, G.; van Veldhuisen, D.J.; Voors, A.A.; Bomer, N.; van der Meer, P. A Clinical Tool to Predict Low Serum Selenium in Patients with Worsening Heart Failure. Nutrients 2020, 12, 2541. [CrossRef]

45. Burk, R.F.; Hill, K.E. Selenoprotein P-expression, functions, and roles in mammals. Biochim. Biophys. Acta 2009, 1790, 1441-1447. [CrossRef]

46. Renner, R. EPA's selenium revision heads into murky waters. J. Environ. Monit. 1999, 1, 67N-68N. [CrossRef]

47. Flohé, L. The labour pains of biochemical selenology: The history of selenoprotein biosynthesis. Biochim. Biophys. Acta 2009, 1790, 1389-1403. [CrossRef]

48. Winkel, L.H.; Vriens, B.; Jones, G.D.; Schneider, L.S.; Pilon-Smits, E.; Banuelos, G.S. Selenium cycling across soil-plant-atmosphere interfaces: A critical review. Nutrients 2015, 7, 4199-4239. [CrossRef] [PubMed]

49. Dennouni-Medjati, N.; Harek, Y.; Tarik, A.; Lahcene, L. Whole blood selenium levels in healthy adults from the west of Algeria. Biol. Trace Elem. Res. 2012, 147, 44-48. [CrossRef] [PubMed]

50. Lachili, B.; Faure, H.; Arnaud, J.; Richard, M.J.; Benlatreche, C.; Favier, A.; Roussel, A.M. Blood micronutrients in Algeria, relationships with sex and age. Int. J. Vitam. Nutr. Res. 2001, 71, 111-116. [CrossRef] [PubMed]

51. Niskar, A.S.; Paschal, D.C.; Kieszak, S.M.; Flegal, K.M.; Bowman, B.; Gunter, E.W.; Pirkle, J.L.; Rubin, C.; Sampson, E.J.; McGeehin, M. Serum Selenium Levels in the US Population: Third National Health and Nutrition Examination Survey, 1988-1994. Biol. Trace Elem. Res. 2003, 91, 1-10. [CrossRef]

52. Wu, Q.; Rayman, M.P.; Lv, H.; Schomburg, L.; Cui, B.; Gao, C.; Chen, P.; Zhuang, G.; Zhang, Z.; Peng, X.; et al. Low Population Selenium Status Is Associated with Increased Prevalence of Thyroid Disease. J. Clin. Endocrinol. Metab. 2015, 100, 4037-4047. [CrossRef]

53. González-Estecha, M.; Palazón-Bru, I.; Bodas-Pinedo, A.; Trasobares, E.; Palazón-Bru, A.; Fuentes, M.; Cuadrado-Cenzual, M.A.; Calvo-Manuel, E. Relationship between serum selenium, sociodemographic variables, other trace elements and lipid profile in an adult Spanish population. J. Trace Elem. Med. Biol. 2017, 43, 93-105. [CrossRef]

54. Mannisto, S.; Virtanen, M.; Mikkonen, T.; Pietinen, P. Reproducibility and validity of a food frequency questionnaire in a case-control study on breast cancer. J. Clin. Epidemiol. 1996, 49, 401-409. [CrossRef]

55. Combs, G.F. Selenium in global food systems. Br. J. Nutr. 2001, 85, 517-547. [CrossRef]

56. Finley, J.W. Selenium accumulation in plant foods. Nutr. Rev. 2005, 63, 196-202. [CrossRef]

57. Bessaoud, O.; Pellissier, J.P.; Rolland, J.P.; Khechimi, W. Rapport de Synthèse sur L'agriculture en Algérie; CIHEAM-IAMM: Montpellier, France, 2019; p. 82.

58. Statistiques du Commerce Exterieur de L'algerie Période: Premier Trimestre de L'année. 2020. Available online: https://www.douane.gov.dz/IMG/pdf/rapport_comext_1er_trimestre_20_vf.pdf (accessed on 30 June 2020).

59. Hartikainen, H. Biogeochemistry of selenium and its impact on food chain quality and human health. J. Trace Elem. Med. Biol. 2005, 18, 309-318, r 2005 Elsevier GmbH. All rights reserved. [CrossRef] 
60. Beladel, B.; Nedjimi, B.; Mansouri, A.; Tahtat, D.; Belamri, M.; Tchanchane, A.; Khelfaoui, F.; Benamar, M.E. Selenium content in wheat and estimation of the selenium daily intake in different regions of Algeria. Appl. Radiat. Isot. 2013, 71, 7-10. [CrossRef] [PubMed]

61. Office Algerien Interprofessionnel des Cereales (OAIC), Algeria-Company Information. Available online: https: //www.zawya.com/mena/en/company/Office_Algerien_Interprofessionnel_des_Cereales-705737/(accessed on 27 July 2020).

62. Adriano, D.C. Biogeochemistry of Trace Metals; Taylor \& Francis Group: Boca Raton, FL, USA, 2017; pp. $22-45$.

63. Shen, J.; Jiang, C.; Yan, Y.; Zu, C. Selenium Distribution and Translocation in Rice (Oryza sativa L.) under Different Naturally Seleniferous Soils. Sustainability 2019, 11, 520. [CrossRef]

64. Sun, H.B. Associations of Spatial Disparities of Alzheimer's Disease Mortality Rates with Soil Selenium and Sulfur Concentrations and Four Common Risk Factors in the United States. J. Alzheimers Dis. 2017, 58, 897-907. [CrossRef] [PubMed]

65. D’Odorico, P.; Carr, J.; Dalin, J.; Dell'Angello, J.; Konar, M.; Laio, F.; Ridolfi, L.; Rosa, L.; Suweis, S.; Tamea, S.; et al. Global virtual water trade and the hydrogical cycle: Patterns, drivers, and socio-environmental impacts. Environ. Res. Lett. 2019, 14, 053001. [CrossRef]

66. Jones, G.D.; Droz, B.; Greve, P.; Gottschalk, P.; Poffet, D.; McGrath, S.P.; Seneviratne, S.I.; Smith, P.; Winkel, L.H. Selenium deficiency risk predicted to increase under future climate change. Proc. Natl. Acad. Sci. USA 2017, 114, 2848-2853. [CrossRef] [PubMed]

Publisher's Note: MDPI stays neutral with regard to jurisdictional claims in published maps and institutional affiliations.

(C) 2020 by the authors. Licensee MDPI, Basel, Switzerland. This article is an open access article distributed under the terms and conditions of the Creative Commons Attribution (CC BY) license (http://creativecommons.org/licenses/by/4.0/). 